\title{
DIVERGENT BELIEFS ABOUT PRODUCTIVITY DESPITE CONCURRENT ENGINEERING AND PULL PLANNING, A CASE STUDY
}

\author{
Ida M. Tvedt ${ }^{1}$
}

\begin{abstract}
Increased productivity is one of the benefits expected when design work in construction is carried out as concurrent engineering using techniques as pull planning. In this context, the evaluation of productivity does not encounter whether the belief of productivity as a concept is homogeneous within the team. A possible consequence of a heterogeneous understanding is unpredictable variety in the behavior of team members'. Efforts to better the performance of design teams through collaborative work processes, so far, have generated limited evidence of the diverse beliefs of productivity. Therefore, the purpose of this paper is to discuss whether the collaborative work processes concurrent engineering and pull planning ensure a homogeneous understanding of productivity. The author of this paper studied a design team in a Norwegian construction project through interviews, observations and document analysis. Designers were asked what productivity is to them, and in what setting it is most evident. The results show that there are conflicting beliefs of what it means to be productive in the team. Also, the project organization does not measure the team's productivity due to the collaboratively structured delivery model. This choice is thought to have an effect on the team's heterogeneous understanding.
\end{abstract}

\section{KEYWORDS}

Perceived productivity, design teams, collaboration, concurrent, pull planning.

\section{INTRODUCTION}

Lean thinking, concurrent engineering, and collaborative work processes have been developed with the hope that, among other things, productivity in the construction industry will be improved (Akanbi et al. 2019). Researchers that report on lean construction argues that projects need reliable workflow because of the unavoidable variability in projects (Ballard 1999a; Howell and Ballard 1998). Pull planning in design is one of the newer additions to the Lean thinking tool-kit, where the aim is to establish a reliable flow in the iterative work performed by designers. The key is to get all experts of the design team together and engage with each other to collaboratively work out the best possible plan for the design phase and thereby reduce waste. These pull techniques are introduced to improve design productivity (Ballard 1999b).

PhD candidate, NTNU - Norwegian University of Science and Technology, Trondheim, Norway, +4790794 323, ida.m.tvedt@ntnu.no, orcid.org/0000-0001-8203-6602 
However, previous research in this field has not prioritized studying how united the understanding of productivity is within teams that are to work close and concurrently. Individuals' belief of what productivity is in the organization influences their behavior (Ruch 1994), and Ballard (1999b) argued that high plan reliability is a consequence of pull planning. Consequently, if the collaborative work processes concurrent engineering and pull-planning better productivity, then these processes must at a level align the team's understanding of the term. This unexplored part of the designers' collaborative dynamic includes why they feel productive and if the work setting matters to these beliefs and feelings. This paper builds on the assumption that a shared understanding of productivity is needed for the reliability that is highlighted in the Lean literature as it predicts behavior.

In this paper, the author reports on selected findings on productivity from a case study of a public Norwegian construction project. The ambition of the paper is to show that there is a divergent understanding of what productivity is and means in design teams despite collaborative work processes that are supposed to align work effort. It is examined how the designers perceive the team's level of productivity, why they feel productive and in what setting they have a feeling of being productive. To conclude, the author addresses and attempts to answer the research question: Do collaborative work processes cultivate a shared belief of productivity in design teams?

\section{THEORETICAL BACKGROUND}

\section{DESIGN PRODUCTIVITY}

A consequence of how productivity is understood and measured in an organization is the shaping of employees' behavior (Ruch 1994; Tangen 2002). Various believes of the term in a team can lead to diverse and unpredictable behaviors. The literature on performance measurement indicates that organizations get what they measure (Brown 1990). What this means is that employees seem to perform well on those aspects of their job that are being measured and valued as a productivity definer. Brown's (1990) findings are supported by Tangen (2002), who argues that productivity is not a fact and that it needs to be defined for employees' to work towards a common goal. Productivity has intuitive meaning for organizations and employees, and need to be coordinated so that employees "speak the same language" and focus their effort in the same direction (Tangen 2002). Also, Ruch (1994) discusses how individuals contribute to group and organizational productivity by focusing on the organizational objectives. From Ruch's research, productivity must be understood and measured based on the goals of the organization. Hence, Ruch's (1994) definition of productivity includes effectiveness (producing the right products or services), efficiency (prudent utilization of resources), and quality (meeting technical and customer specifications). Also, Duffy (1998) reports that efficiency and effectiveness are two key features defining design productivity. In a report from 1998, Duffy describes efficiency as benefits/cost, and benefits as the product or the process, and cost as the value of capital, labor, and overheads. Effectiveness is explained in vaguer terms: a measure of the achievement of the desired effect or outcome.

Productivity in construction has been much studied by researchers and practitioners to increase profit in the construction industry (McGeorge John F. 1988; Park Hee-Sung et al. 2005). Former research has mostly focused on productivity at construction sites where the transformation view (Koskela 1999) or labour productivity, defined as output/ input or input/ output, are more applicable (Park Hee-Sung et al. 2005). In simple terms, labour productivity is about producing the product as fast as possible, keep it one 
dimensional, and avoid iterations. Even so, the measure of production productivity is not a straight forward task as most processes have several inputs and outputs, and what is productive changes from what level it is analyzed. Also, Bertelsen and Koskela (2002) argue that the transformation view should be complemented with the perspectives of flow and value to increase performance. Then productivity as a goal is replaced by flow and value creation. This paper, however, is limited to elaborate on productivity as a fairly specific concept (Tangen 2002).

The challenge of defining productivity increases in the setting of design, due to the nature of work. Design work, also described in the literature as white-collar work (Schroeder et al. 1985) or knowledge work (Ramírez and Nembhard 2004), is more complex as tasks are not fixed, seldom have a standard production time, and can be performed in different ways. In a design team, work-hours are challenging to track as the designers use much of their time on indirect production tasks (Randolph et al. 1999), as communicating problems and learning clients' needs. Also, value-generating iteration is essential, and variability of outcome desirable (Ballard 2000). Thus, a measure of labor productivity will not give a sufficient measure of design productivity as it is characterized as more subjective and can be understood as an abstraction.

\section{COLLABORATIVE WORK PROCESSES FROM LEAN THINKING}

The principles of Lean has gained significant attention in the construction industry, much due to the possibility of improving quality, efficiency (Akanbi et al. 2019), and productivity (Aziz and Hafez 2013). Lean thinking is all about people and creating a culture of continuous improvement. With Lean, it is through collaborative work processes that teams find innovative solutions to productivity. Ballard and Howell (1998) describe that this collaborative coordination of action rests on system thinking, meaning that the coordination aims to align project actor's behavior.

Two collaboration based Lean techniques were to a degree present in the studied project. Thus, the paper is limited to elaborating on the effect of concurrent engineering and pull planning. In the following sections, the characteristics of the two techniques are presented to be a context for the finding as it explains why the techniques should contribute to a shared belief of productivity.

Concurrent engineering (CE). Ballard (1999b) describes CE as the integration of product and process design. In contrast to the traditional project management, CE management integrates those in the project organization responsible for the production of the product and those involved in the process of designing the product. The goal is to, among other things, obtaining the most favorable products in a productive matter (Aziz and Hafez 2013). It is a management philosophy that focuses on communication and transparency, and to succeed it requires main actors to collaborate. Ballard and Howell (2003) list CE as a technique that can help reduce negative iteration in the design process in construction.

Pull planning. Traditional design management manages workflow through plans, regardless of the current project situation, also described in the literature as push-planning (Ballard 1999b). Pull planning is another way of thinking about workflow, where the approach is collaboratively focusing on what can be done and not what should be done in the current project situation. Also, Tsao et al. (2014) describe pull planning as a process that encourages the project performers to early collaborate on design solutions. Hence it can be a management tool to assist concurrent engineering in aligning team members' effort. 


\section{RESEARCH DESIGN}

A focus on a divergent understanding of productivity, reported on in this paper, came as an emergent theme in the analysis process of a larger qualitative case study. The original study explores the relationship between psychological safety, digital mindsets, and productivity in a design team in a public Norwegian construction project. The study aims for knowledge on how design teams can better face the digital transformation of the industry.

Due to the emergent origin of this paper, the analysis process has been inductive, where the research question was formulated after the collection of data and the first process of coding. To clarify this development, the following sections describe the initial case study design and the analysis process leading to the results of this paper.

The researcher chose to apply a case study approach in line with the recommendations of Yin (2003) to address the initial research questions in hand, enabling an in-depth study of the relationship between the three phenomena. The research has the characteristics of a case study as it reports on a relatively small sample, a single project, selected purposefully to secure an information-rich case (Preston 2002 p. 230). The strategy to purposefully select a case has been an intensity sampling, where the purpose is to identify a case that can manifest the phenomenon of interest (Preston 2002 p. 234). The studied design team focuses on productivity; hence it is a sample of sufficient intensity and thereby a setting to provide a deeper understanding rather than an empirical generalization of the issue being studied. The unit of analysis is, therefore, the team that shares the same project culture.

The theory of productivity has been much researched. Therefore, instead of providing descriptive knowledge contributing to the definition of what productivity is, the presented research reports on relational knowledge (Downs and Fawcett 1999). The researcher takes a social perspective when analyzing the relationship between collaborative work processes and designers' understanding of productivity. Behaviors and systems are what is being analyzed to understand if a homogeneous understanding of productivity is an effect of concurrent engineering and pull-planning. Thus, the researcher takes the metatheoretical stance of Critical Realism following Sayer (2000), where the aim is to explain within a defined context and that observable phenomena as productivity provide credible data. Align with Critical Realism; the objective is to elaborate on the research question and not to claim that the presented understanding is the only truth (Klakegg 2016).

\section{PROJECT DESCRIPTION}

The studied construction project was identified through a discussion with the company Undervisningsbygg Oslo, a Norwegian public sector client. Undervisningsbygg is the largest property manager in Oslo that develops, builds, and distributes public buildings ("Undervisningsbygg Oslo KF" n.d.). The studied case is a new complex building project, serving several purposes, with a total area of $6514 \mathrm{~m}^{2}$ (70,105 square feet).

The project delivery model is labeled as a Norwegian "samspillsentreprise," in English understood as a partnering project or a collaborative delivery model. At the time this study was documented, the construction project was in the second part of the detail phase of the project's life cycle.

During the time the author observed the project, the work setting and process had similarities to the elements workflow and pull-planning, known from Lean thinking (Howell and Ballard 1998). The project manager managed the project as one coherent 
operation where all essential actors in design and production (the project owner, the architect, the consultants, the contractor) were involved, and they had all been engaged from early on in the design phase. This type of building process is described by Ballard (1999b) as concurrent engineering. Also, the design manager performed a version of pull planning. For example, it was observed in a meeting that the design manager engaged the design team to update the workflow for the next month based on the current state of the project so that they best could move forward with the project with a basis in the current situation. Also, in interviews, the design manager talked about this process using the term pull planning. Due to these collaborative work and management characteristics, this paper addresses the Lean community with the research question and the concern about the findings of the team's heterogeneous beliefs of productivity.

\section{DATA COLLECTION}

\section{PARTICIPANTS}

At the time of the data collection, the list of designers included over 50 contributors. Thus, interviewees for the in-depth interviews were selected in collaboration with the project's design manager based on the designers' impact on the project and how much they had participated in interdisciplinary processes with the team. The result was 14 informants representing six different companies and nine trades, listed in Table 1.

Table 1: Participants by trade

\begin{tabular}{cccc}
\hline Trade & $\begin{array}{c}\text { Number of } \\
\text { participants }\end{array}$ & Trade & $\begin{array}{c}\text { Number of } \\
\text { participants }\end{array}$ \\
\hline Project manager & 1 & Landscape architect & 1 \\
\hline Design manager & 1 & $\begin{array}{c}\text { Electrical engineering } \\
\text { consultant }\end{array}$ & 1 \\
\hline $\begin{array}{c}\text { Former design } \\
\text { manager }\end{array}$ & 2 & $\begin{array}{c}\text { Structural design } \\
\text { engineer }\end{array}$ & 3 \\
\hline BIM-coordinator & 2 & $\begin{array}{c}\text { Consultant for precast } \\
\text { concrete }\end{array}$ & 1 \\
\hline Architect & 2 & & \\
\hline
\end{tabular}

\section{PROCEDURE}

The data collection took place over two months, with the majority collected within a month. The instruments of data collection for the analysis in this paper were a review of project documents, 15 interviews, and nine meeting observations. The data were collected personally by the researcher, and all information and interviews were in Norwegian. Transcripts of recorded interviews, observation notes, and project documents were uploaded to the qualitative data analysis software NVivo, which helped organize the triangulation of data. All statements and informants have been anonymized, and details about episodes have been anonymized by replacing parts with, for example, [an episode].

Project documents. The project plan served as support for triangulation, which provided important background information of the team.

Observation. The author logged 30 hours of observation. The majority of this time was spent in the background of different types of meetings, but also in informal settings 
such as lunches and breaks. Before the data collection, an observation protocol was designed to help the researcher to identify characteristics of, in this paper, productivity. The protocol is created from the findings of a literature search early in the development of the case study. Observation data were collected as notes, video recordings, and photos.

Informative interviews. The researcher conducted two informative interviews, one of the project's project manager and one of the team's design manager. The informative interviews were used to gain knowledge of the project and the design team and how best to proceed with the observations. The interview followed a semi-structured format based on a protocol developed in advance by the researcher.

In-depth interviews. The researcher conducted 14 in-depth explorative interviews with members of the design team and the design manager. The interviews followed a semistructured format based on a protocol developed by the researcher. Before the interviews, a simplified interview guide based on the protocol was sent out for the interviewees to familiarize themselves with the themes of the study and to give them the opportunity to ask questions beforehand.

\section{RESEARCH FINDINGS AND DISCUSSION}

\section{DIVERGENT UNDERSTANDING OF PRODUCTIVITY}

It tends to be an intrinsic belief that when people are put together as in a team and are managed well, they aim to be productive together (Hamilton et al. 2003). However, if Ruch (1994) is correct about team members' behavior being shaped by their belief of what productivity is, and they do not share the belief, their effort to collaboratively be productive may not pay off. Therefore, in the first part of this discussion, the author takes a closer look at how productivity is defined by the individuals of the design team.

The interviewees in the case study were asked what productivity means to them. When looking closer at the informants' answers, the opinions are split, and three categories became evident for the researcher; speed, the delivery, and plans. Examples of the answers belonging to each category are listed in Table 2 on the next page.

As the quotes in Table 2 reveals, for some informants it is important for the productivity that the work processes goes fast (speed) and that the designers are eager (engagement). This belief of productivity seems to value the inputs (work-hours), and this view has similarities to Park Hee-Sung et al.'s (2005) definition of labor productivity. Other interviewees balance time with quality of what they produce, meaning that processes need to go fast, but to be productive, they need to do the right things with all needed information (no waste). This view is more in line with Ruch's (1994) definition of design productivity consisting of effectiveness, efficiency and quality. For others, productivity is defined by deliverance (output). Some view productive deliverance as something that is forced, others view deliverance as productive when everyone can agree that it has the appropriate quality. The process of agreeing is more in line with the mindsets Ballard (1999b) links to CE and pull planning. The last grouping of belief on what productivity is entails plans and frameworks, closely connected to goals and subgoals (goal achievement). Goal achievement goes beyond delivery and has similarities to what Duffy (1998) explained as effectiveness (the achievement of the desired outcome). 
Table 2: Informants' answer to what productivity means to them

\begin{tabular}{|c|c|c|}
\hline Speed & The delivery & Plans \\
\hline $\begin{array}{l}\text { So [productivity] is if it } \\
\text { goes fast". } \\
\text { "[Productivity is] the right } \\
\text { speed, not too high and } \\
\text { not to low" } \\
\text { "It is about being eager } \\
\text { and not wait for things" } \\
\text { "Efficiency is not just that } \\
\text { the building gets finished } \\
\text { or that the politicians say } \\
\text { that it must be done. It is } \\
\text { the price and the time" } \\
\text { "Productivity is when you } \\
\text { manage to work efficiently } \\
\text { with your tasks and solve } \\
\text { them in the shortest } \\
\text { possible time. That means } \\
\text { that you have to solve } \\
\text { things at the right time, } \\
\text { with the right basic } \\
\text { information so you do not } \\
\text { have to go back" }\end{array}$ & $\begin{array}{c}\text { "Productivity for me right now } \\
\text { is to deliver the product, the } \\
\text { drawings. At the same time, } \\
\text { my role now is a specialty } \\
\text { coordinator. That is also a } \\
\text { product, but it is hard to } \\
\text { measure" } \\
\text { "[Productivity] is depended on } \\
\text { your own expectations to } \\
\text { what you had in mind or was } \\
\text { forced to deliver or clarify } \\
\text { over a given period of time" } \\
\text { "Productivity for me is that we } \\
\text { have an easy way to report } \\
\text { updates in the model, that is } \\
\text { faster for us and the } \\
\text { designers to get an overview } \\
\text { and trace changes, It is a } \\
\text { productivity assurance on } \\
\text { what has been done" } \\
\text { "[Productivity] is when you } \\
\text { get things done at the right } \\
\text { time, and that everyone that } \\
\text { needs to be involved is } \\
\text { involved and agrees that we } \\
\text { can move on with what we } \\
\text { got" } \\
\text { "I think about productivity in } \\
\text { relation to expected } \\
\text { deliverance, that the project } \\
\text { owner gets what they expect } \\
\text { at the right time" }\end{array}$ & $\begin{array}{l}\text { "Productivity for me is plans } \\
\text { and frameworks" } \\
\text { "Productivity is when we } \\
\text { plan and manage to } \\
\text { proceed with what we have } \\
\text { planned in a good way" } \\
\text { "The productivity level is } \\
\text { connected to if the } \\
\text { productivity is in favor of the } \\
\text { total progress, and that we } \\
\text { are working with the right } \\
\text { things at the right time" } \\
\text { "Productivity is when we } \\
\text { have followed the progress- } \\
\text { plan" } \\
\text { "Productivity for me is when } \\
\text { we have clearly defined } \\
\text { goals, and that we have a } \\
\text { plan that we are strictly } \\
\text { following in accordance with } \\
\text { sub-goals. You must } \\
\text { approach the project } \\
\text { according to what is most } \\
\text { important and when. So the } \\
\text { key to efficiency is to plan } \\
\text { the process" }\end{array}$ \\
\hline
\end{tabular}

\section{DIVERGENT BELIEFS OF THE TEAM'S PRODUCTIVITY}

In the prior section, findings revealed that informants have a divergent belief of what it means to be productive as a designer in a design team. The informants' answers from Table 2 can be summed up in one definition of productivity; to have and to follow a plan that ensures that that the team is delivering the right things at the right time. This vague definition that includes “everything”, confirms Randolph et al.'s (1999) concern about knowledge work to be challenging to define. Further, the designers were asked about productivity in the current project that the author studied to bring the issue closer to the designers' everyday working life with collaborative work process.

\section{How to recognize productivity}

When asked how they recognize productivity in the project, some team members answered that productivity is "obvious" when they work closely together. The design manager expressed that when the process goes by itself, then one can see that it is "...fun to work for everyone". One informant highlights the meetings as an arena to evaluate productivity and expresses that productivity is a phenomenon that occurs through collaboration and pulling together: 
"From the mood in the meeting, you can quickly figure out if you are riding a wave or if you are climbing a wave. If the conversation is characterized by understanding and indulgence and you try to help each other, then I think there is good drive and good efficiency because then everyone contributes".

When the researcher entered the project, there was not a measurement of productivity, helping the project manager and the design manager to evaluate the productivity of the design team. If Brown (1990) is correct about the organization getting what they measure, then an absence of a measuring system can have an effect on the team's heterogeneous belief of productivity. Simultaneously, team members mentioned that the BIM-model was used to assess the individual's productivity: "We have set days where we upload things in the models for review. Then we see it. If there are then deviations in relation to other specialties for example. And you would see if people have worked and been productive". This comment reveals that the informant associates productivity with time and delivery, and it can be understood from the comment that a team member can be productive as long as something in the BIM-model has been produced. However, the design manager expressed that a quantitative measure of productivity would be of help in the project, but that the project organization did not want to use the measures that the construction company typically provided, much due to the chosen collaborative work processes. Hence, to identify unproductive team members, the design manager observed their behavior in meetings and tracked their deliveries. What is interesting, even though it would be of help, is that the design manager does not feel that there is a pressing need to measure productivity because of the collaborative structure:

"We are equal to the architects and the rest of the team, so it is the project manager that handles the progress. Everything depends on the hours spent in this phase, and it is [the project manager]'s project and he is the one that controls the money-flow".

\section{Beliefs about the team's productivity level}

When asked about the team's productivity level, most interviewees answer that the productivity level has varied, but that now it is somewhere in-between, above average. This belief exists despite the project being delayed by a year. Why some team members evaluate the project as productive even though there is a delay, could be a consequence of quality being the value the designer understand as productivity. An informant expressed why it is not high: "We have so many consultants from one company that lower productivity". The order of the work is also seen as a hindrance to progress. One informant expressed that there have been too many changes from the preliminary phase, so they had to redo the deliveries. It was brought up that this was a consequence of the construction company being brought into the process too late. From this knowledge, it is debatable if the concurrent engineering process has not been proceeded successfully to harvest the benefits mentioned by Ballard and Howell (2003). Also, the following comment by a team member reveals that doing "the right things at the right time" is still an issue:

"In this project, we are doing things too early. We are not putting the shovel in the ground before next year, and it is an additional year before the electrician will start to pull cables. So to say that we will have the drawings finished this summer is to say that we are to be finished too soon. [...] If those drawings contain a lot of mistakes or they are based on wrong decisions or 
the wrong foundation, then it has to be redone, and then it is no longer productive".

\section{Situations where they feel productive and why}

To capture the designers' belives about the term productivity, they were asked about a situation where they get the feeling of being productive in the project. Meetings were repeated by the interviewees. The majority feel they are most productive when they physically sit together, and especially in specialty meetings. For example, one informant said: "In [an episode] we had two meetings, and we presented to each other the issues, and after we had pondered a little, we could offer a solution that suddenly turned out to cover several needs". In this episode, the team presented their ideas to each other, spoke up, and that the meeting participants were not rejected for stating their opinion. Through the process of "pondering a little" they shared their knowledge in a manner that can be understood as experimenting. This interdisciplinary process would not be productive if the team did not respect each other's knowledge and pulled together. These findings indicate that the process of pull planning and concurrent engineering defined by Ballard (1999b) cultivates team members' feeling of being productive despite them having various beliefs of the definition.

Another example of a situation where the team seems to feel productive is from a meeting observation where the objective was to pin down sub-goals and decide the order of deliveries before the summer. The episode was a collaborative process managed by the design manager, together with the members representing the central specialties in the design team. The leader behavior of seeking feedback from the team and inviting engagement shows that he respects their knowledge and acknowledges his limitation regarding technical details. Through a team discussion, they ensure that they produce the right drawings and deliveries in the right order, in accordance with the pull planning technique (Ballard 1999b) and in line with Poirier et al.'s (2015) definition of effectivity.

However, physically, collective problem solving is not the most productive setting for all interviewees: "Right now when I have so much to do, I need quietness to feel productive. [...] I need enough hours at my desk, and not just go to meetings". Interviewees described that for settings where the team members work individually to be productive, there must be trust in that everyone pulls together and that the team will respect the work one produces. For example, one interviewee says:

"You can be very productive when you sit in meetings discussing and deciding things, when you take phone calls, research things, order products or have a dialogue with a supplier. But it feels very nice when you produce a drawing where you gather all the information you have received".

To feel good, the interviewee is dependent on trusting the information from others and believe that they have good intentions for the project. If not, the designer will produce a delivery that might be in danger of rework. To gain a deeper understanding of these situations of feeling productive, interviewees were asked why they feel productive. Examples of the responses are listed in Table 3, where answers are connected to collaborative mechanisms. The results give the impression that there are collaborative mechanisms working in the team that cultivates their feeling of being productive. The results give an indication that there is a link in the studied project between the collaborative working processes and productivity as an abstraction. 
Table 3: Feeling of productivity related to collaborative mechanisms

\begin{tabular}{|c|c|}
\hline Responses to why the interviewees feel productive (interviews) & $\begin{array}{l}\text { Collaborative } \\
\text { mechanisms }\end{array}$ \\
\hline $\begin{array}{c}\text { "I feel productive every day. But I felt productive in this one episode } \\
\text { where it was crucial to get the solution in place very quickly because a } \\
\text { lot was dependent on it. But it was not a decision that could come the } \\
\text { week after it was introduced. I felt productive because I said quite early } \\
\text { that it was not a quick answer to the issue, and that the solution } \\
\text { needed maturing. So we had to add time so that it could mature to } \\
\text { achieve productivity". }\end{array}$ & $\begin{array}{l}\text { Members are not } \\
\text { reluctant to } \\
\text { discuss. }\end{array}$ \\
\hline $\begin{array}{c}\text { "It can be as easy as seeing that you have produced something. That } \\
\text { feels good". }\end{array}$ & Motivation \\
\hline $\begin{array}{l}\text { "It feels very good when we deliver something together with others, } \\
\text { and that we get positive feedback from the other end that says 'good, } \\
\text { this was what we needed". }\end{array}$ & $\begin{array}{l}\text { Seeking/ giving } \\
\text { feedback }\end{array}$ \\
\hline $\begin{array}{c}\text { "You get a feeling that there is productivity in the project when you see } \\
\text { the communication that flows. I went home at four yesterday, and when } \\
\text { I was back at nine today, I had received } 20 \text { emails, where } 15 \text { were } \\
\text { directly related to design-tasks". }\end{array}$ & $\begin{array}{l}\text { Accountability - } \\
\text { everyone pulls } \\
\text { together }\end{array}$ \\
\hline $\begin{array}{c}\text { "I feel productive when I can answer the questions that they are } \\
\text { wondering about there and then and that we can meet whatever they } \\
\text { want. [...] You are in the meeting, and you represent [a company], then } \\
\text { you should be able to answer. Otherwise, to be frank, you should not } \\
\text { be here". }\end{array}$ & Speaking up \\
\hline $\begin{array}{c}\text { "I feel productive when everyone contributes, and you see that people } \\
\text { thrive, and things that are planned get done". } \\
\text { "When it is not just you, but that everyone is pleased with the } \\
\text { solution". }\end{array}$ & $\begin{array}{l}\text { Going forward is a } \\
\text { collaborative } \\
\text { commitment }\end{array}$ \\
\hline $\begin{array}{c}\text { "I can feel when I am productive. [An episode] then it went fast from I } \\
\text { was assigned the task until I delivered the product. And no-one } \\
\text { disagreed with what I had produced". }\end{array}$ & $\begin{array}{l}\text { Members respect } \\
\text { on another's } \\
\text { knowledge }\end{array}$ \\
\hline
\end{tabular}

\section{CONCLUSION}

As written about in the literature, design productivity has been proven in this paper to be a complex and vague phenomenon for members of design teams.

The research question - Do collaborative work processes cultivate a shared belief of productivity in design teams? - speaks directly to the academic discussions of how delivery models affect behavior. The findings suggest that despite concurrent engineering and the design manager's effort of bringing the team into a pull-planning process, there are divergent beliefs of what productivity means in the project. It was found that the project had chosen to not measure productivity due to the collaborative delivery model. This choice can be a contributing factor to the heterogeneous findings as the team members did not get clarity to what was seen as productive by the management. Simultaneously, it is evident that the team members felt more productive in face-to-face collaborative situations where for example goals became transparent for all involved. Hence, collaborative work processes are proven to cultivate individuals feeling of being productive, but not directly cultivate a shared belief of the definition of productivity. What is interesting is that productivity at a conceptual level seems to have a different meaning 
for the designers, then when one brings the phenomena down at their everyday level. This could mean that there are project mechanisms that affect the team members' beliefs of productivity at some level.

\section{FURTHER RESEARCH}

The similarity to when or why the designers in the team feel productive and the characteristics of the phenomenon of psychological safety is an interesting angle for further research. For example, Gilkson et al. (2016) explain that the process of collective intelligence and knowledge sharing, as observed in the design team, are psychological safety behaviors that can cultivate common goals and a deeper understanding of the needs of the team. It is under face-to-face collaboration that team members feel most productive. A possible explanation for this is that these positive collaborative processes indirectly inline their belief of productivity to the goals of the project organization.

Also, initially in this paper's discussion, this statement was put forward: "if team members do not have the same understanding of what productivity is, then their effort to collaboratively be productive may not pay off". This paper is limited to showing that there is a divergent understanding of productivity. Hence, the statement has not been discussed, but finding indicates that the proposition could be the starting point of research addressing if individuals' beliefs about productivity affect the team's measurable productivity.

\section{ACKNOWLEDGMENT}

I would like to express my sincere gratitude to Undervisningsbygg and the project organization that opened their doors for the presented study. Also, I thank the project manager and design manager of the project for assistance and insightful discussions and the design team for their time, patience, and interest in participating in the study. Finally, thanks to my always supporting doctoral supervisor for knowledge sharing and assistance.

\section{REFERENCES}

Akanbi, O. A., Oyedolapo, O., and Steven, G. J. (2019). "Chapter 12 - Lean Principles in Construction." Sustainable Construction Technologies, V. W. Y. Tam and K. N. Le, eds., Butterworth-Heinemann, 317-348.

Aziz, R. F., and Hafez, S. M. (2013). "Applying lean thinking in construction and performance improvement." Alexandria Engineering Journal, 52(4), 679-695.

Ballard, G. (1999a). "Improving Work Flow Reliability." Proc. $7^{\text {th }}$ Ann. Conf. Int. Group for Lean Construction, Berkeley, CA, USA, 275-286.

Ballard, G. (1999b). "Can pull techniques be used in design management?" Conf. on Concurrent Engineering in Construction: challenges for the new millennium, CIB Int. Council for Research and Innov. in Building and Construction, Helsinki, Finland.

Ballard, G. (2000). "Positive vs negative iteration in design." Proc. $8^{\text {th }}$ Ann. Conf. Int. Group for Lean Construction, UK, Brighton.

Ballard, G., and Howell, G. (2003). "Lean project management." Building Research \& Information, 31(2), 119-133.

Bertelsen, S., and Koskela, L. (2002). "Managing the Three Aspects of Production in Construction." Proc. 10 $0^{\text {th }}$ Ann. Conf. Int. Group for Lean Constr., Gramado, Brazil, 13-22.

Brown, M. G. (1990). "You get what you measure: Engineering a performance measurement system." Performance + Instruction, 29(5), 11-16. 
Downs, F., and Fawcett, J. (1999). The Relationship of Theory and Research. F.A. Davis Co., Philadelphia, Pa.

Duffy, A. H. B. (1998). "Design Productivity." The Design Productivity Debate, A. H. B. Duffy, ed., Springer London, 1-9.

Glikson, E., Harush, R., Kim, Y. J., Woolley, A., and Erez, M. (2016). "Psychological Safety and Collective Intelligence in Multicultural Globally Dispersed Teams." INGRoup 2016, INGRoup, Helsinki.

Hamilton, B. H., Nickerson, J. A., and Owan, H. (2003). "Team Incentives and Worker Heterogeneity: An Empirical Analysis of the Impact of Teams on Productivity and Participation." Journal of Political Economy, 111(3), 465-497.

Howell, G., and Ballard, G. (1998). "Implementing Lean Construction: Understanding and Action." Proc. $6^{\text {th }}$ Ann. Conf. Int. Group for Lean Construction, Guarujá, Brazil.

Klakegg, O. J. (2016). "Ontology and Epistemology." Designs, Methods and Practices for Research of Project Management, Routledge, England, 57-66.

Koskela, L. J. (1999). "Management of production in construction: A theoretical view." Proc. $7^{\text {th }}$ Ann. Conf. Int. Group for Lean Construction, Berkeley, CA, USA.

McGeorge John F. (1988). "Design Productivity: A Quality Problem." Journal of Management in Engineering, 4(4), 350-362.

Park Hee-Sung, Thomas Stephen R., and Tucker Richard L. (2005). "Benchmarking of Construction Productivity." J. Constr. Engine. and Management, 131(7), 772-778.

Preston, M. (2002). "Purposeful Sampling." Qualitative Research \& Evaluation Methods, SAGE, London, New Delhi.

Ramírez, Y. W., and Nembhard, D. A. (2004). "Measuring knowledge worker productivity: A taxonomy." Journal of Intellectual Capital, 5(4), 602-628.

Randolph, T. H., Coco, K. Q., E. Sanvido, V., and Parfitt M., K. (1999). "Conceptual Model for Measuring Productivity of Design and Engineering." Journal of Architectural Engineering, 5(1), 1-7.

Ruch, W. A. (1994). "Measuring and Managing Individual Productivity." Organizational Linkages: Understanding the Productivity Paradox, The National Academies Press, Washington, D.C, 105-130.

Sayer, A. (2000). Realism and Social Science. SAGE Publications Ltd, London; Thousand Oaks, Calif.

Schroeder, R. G., Scudder, G. D., and Anderson, J. C. (1985). "Measurement of White Collar Productivity." Int. J. of Operations \& Production Management, 5(2), 25-34.

Tangen, S. (2002). "Understanding the concept of productivity." The 7th Asia Pacific Industrial Engineering and Management Systems Conference, Taipei, China.

Tsao, C. C. Y., Draper, J., and Howell, G. A. (2014). "An Overview, Analysis, and Faciliation Tips for Simulations That Support and Simulate Pull Planning." Proc. $22^{\text {nd }}$ Ann. Conf. Int. Group for Lean Construction, Oslo, Norway.

"Undervisningsbygg Oslo KF." (n.d.). Oslo kommune, Company webpage. Accessed Januar 2, 2020.<https://www.oslo.kommune.no/politikk-og-administrasjon/etaterforetak-og-ombud/undervisningsbygg-oslo-kf/>.

Yin, R. K. (2003). Case Study Research: Design and Methods. SAGE. 